\title{
Translabyrinthine Approach for Resection of Vestibular Schwannoma
}

\author{
Yening Feng ${ }^{1}$ Neil S. Patel ${ }^{1}$ Jamie J. Van Gompel ${ }^{1,2}$ Matthew L. Carlson ${ }^{1,2}$ \\ ${ }^{1}$ Department of Otolaryngology-Head and Neck Surgery, Mayo Clinic, \\ Rochester, Minnesota, United States \\ 2 Department of Neurosurgery, Mayo Clinic, Rochester, Minnesota, \\ United States \\ Address for correspondence Matthew L. Carlson, MD, Department of \\ Otolaryngology-Head and Neck Surgery, Mayo Clinic, Rochester, MN \\ 55905 (e-mail: carlson.matthew@mayo.edu). \\ J Neurol Surg B 2019;80(suppl S3):S286.
}

\begin{abstract}
Objectives This video describes the surgical indications, relevant anatomy, and surgical steps of routine translabyrinthine surgery for gross total resection of sporadic vestibular schwannoma.

Design The procedure is presented through a surgical instructional video.

Setting The surgery took place at tertiary skull base referral center.

Parcipant A 47-year-old patient reported with nonserviceable hearing, frequent

Keywords

- translabyrinthine

- vestibular schwannoma

- acoustic neuroma episodes of vertigo, recurrent severe headache, and a small unilateral right sided vestibular schwannoma.

Results Gross total resection with preservation of facial nerve function was achieved. Conclusion This instructional video documents the surgical steps and relevant anatomy for translabyrinthine resection of vestibular schwannoma.

The link to the video can be found at: https://youtu.be/CJ2vKMLs7al.
\end{abstract}

Conflict of Interest

None.

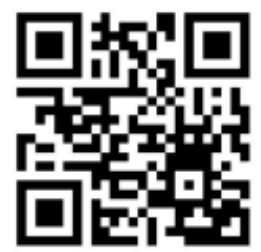

received

May 30, 2018

accepted after revision

November 11, 2018

published online

March 1, 2019 www.thieme.com/skullbasevideos

www.thieme.com/jnlsbvideos 10.1055/s-0039-1677856. ISSN 2193-6331.
License terms

(c) 2019 Georg Thieme Verlag KG
Stuttgart · New York

(c) (i) $\ominus$ (\$) 